
6 Poland.

\title{
Should I shrink or should I flow? - body size adjustment to thermo-oxygenic
} niche

\section{Running title: Thermo-oxygenic ecological niche}

\author{
Authors: Aleksandra Walczyńska ${ }^{1}$, Agnieszka Gudowska ${ }^{1}$, Lukasz Sobczyk $^{1}$
}

${ }^{1}$ Institute of Environmental Sciences, Jagiellonian University, Gronostajowa 7, 30-387 Krakow,

*Correspondence to: aleksandra.walczynska@uj.edu.pl

Phone: +48 126645203, fax: + 48126646912

Authorship: AW conceptualized the idea and acquired the data; AW and ŁS conducted the PCA analysis; AG constructed the phylogenetic tree and conducted all the phylogenetically corrected analyses; AW, AG, ŁS prepared data visualization; AW wrote the initial draft; AG and $Ł S$ reviewed and commented on the manuscript.

Data and materials availability: All data are available in the original articles or in the supplementary materials. The data supporting the results will be archived in a public repository (Dryad) and the data DOI will be included at the end of the article.

Keywords: ecological niche, generalists, oxygen, specialists, rotifers, temperature 


3

4

55

6

7

8

99

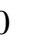

1

\section{Abstract}

Organisms adjust their size according to temperature and supposedly also respond to its negative covariate, oxygen. To what extent is size a response to temperature or oxygen? We analyzed the thermo-oxygenic niche for the community of 188 rotifer species. Evolution toward ranges of thermal tolerance occurred separately from evolution toward their optima. Body size was adjusted to both temperature and oxygen, but the cues for body size response differed; size was either driven by optimal temperatures or by the oxygen tolerance range. Animals are clearly separated into generalists or specialists, and their evolutionary body size adjustment is realized through differential responses to environmental factors. Oxygen is as important as temperature in the evolution of body size and ecological niche preference. An important conclusion from this study is that oxygen deprivation following global warming seems to be as problematic for the studied organisms as the temperature increase itself. 


\section{Introduction}

To understand the link between the performance of organisms and their environment is one of the

Grand Challenges in organismal biology (Schwenk et al. 2009), especially in the context of abrupt climatic change (Allen et al. 2018). The general prediction is that body size decrease is a third universal response to global warming, especially in aquatic systems, following the geographic and phenological shifts in species distribution (Daufresne et al. 2009). Understanding the body size response to environmental factors is essential because this trait is unique (Kozłowski 2006). It can be perceived mutually as a morphological, physiological and life history trait, interconnecting the fields of ecology, evolution, and physiology. Despite the fundamental role of body size response, the key question of how animals become the size they are still awaits a satisfactory answer (Callier \& Nijhout 2014). What kind of negative changes should we expect in the communities exposed to warming? Can we prevent at least some of these negative changes? Which actions should we undertake? What organisms do we save first? These urgent questions are not trivial for many reasons; however, the fundamental question of how organisms interact with their thermal environment remains unanswered. The crucial role of body size is that this trait is the major target of selective response on the organismal level (Kozłowski 2000), and such individual response affects the whole community through the plethora of possible ways including trophic interactions, dispersal abilities, habitat exploitation, nutrient cycling and others (Hildrew et al. 2007).

Ambient temperature is the most influential variable that shapes organismal strategies, from physical effects, through evolutionary influence, to ecological interactions (Schmidt-Nielsen 1990; Willmer et al. 2000; Begon et al. 2006). All life forms are equipped with mechanisms to detect and react to changing temperatures. Body size adjustment is an example of such a reaction. 
It is a phenomenon observed both genetically and phenotypically and is an assumed driver for interspecific Bergmann's rule (Bergmann 1847) and the intraspecific temperature-size rule

(Atkinson 1994). Body sizes changed with seasonal variations in temperature according to the rule "when it's hot, shrink" in both small-scale (Kiełbasa et al. 2014) and large-scale studies (Horne et al. 2016; Horne et al. 2017). The empirical evidence for the direction of thermally induced body size changes on both the genetic and phenotypic levels in the same species is scarce, and it provides an ambiguous view of either positive covariance, as in Brachionus plicatilis rotifer (Walczyńska et al. 2017) or the negative one, as for the case of Drosophila pseudoobscura (Taylor et al. 2015).

Most other environmental variables are at least partly positively correlated with temperature.

Oxygen is an exception because it is negatively correlated with temperature (Wetzel 2001 for aquatic systems). Oxygen stress often occurs at higher temperatures, because the energetic al. 2012; Horne et al. 2015; Horne et al. 2017). It is caused by the fact that breathing under water is much more challenging than in air because of the much slower oxygen diffusion in the former system (Verberk et al. 2011). Oxygen stress at higher temperatures has been suggested to cause the cell size to decrease to enhance the efficiency of oxygen transport to the mitochondria (Woods 1999), and as a result, the whole body shrinks (Atkinson et al. 2006). Animals anticipate oxygen deficiency when experiencing a temperature increase (Walczyńska et al. 2015). Thus, they face the ecophysiological dilemma of either accepting this challenge and adjusting their cell (and body) size to overcome the reduced aerobic metabolism efficiency or behaviorally adapting 
are too stressful, while those lacking the ability to respond are immediately at risk when escape is not possible. To understand whether and how organisms respond to change, we first need to identify the exact environmental response cues and initiation mechanisms. Including oxygen concentrations as a covarying parameter in the studies on size-to-temperature response facilitates the interpretation of the results (Kiełbasa et al. 2014; Walczyńska \& Sobczyk 2017). A main question has emerged: what exactly drives body size responses?

Here, we used an exceptional field model to study evolutionary outputs that could not be experimentally tested in the laboratory. We scrutinized data published 30 years ago in the new context of thermo-oxygenic niche construction within an aquatic community. The original data were provided by Bērzinš and Pejler, who reported the results of planktic, periphytic and benthic rotifer sampling from approximately 600 different water bodies (lakes, ponds, rivers and mires) in Sweden for approximately 40 years. The authors related the occurrence of each species to temperature (Bērzinš \& Pejler 1989b) and oxygen concentration (Bērzinš \& Pejler 1989a), among other factors. The data, supplemented with information on species-specific body sizes, gave us a unique opportunity to study the interspecific size response to subtle aspects of the environment at the macroevolutionary scale, in the context of ecological niche.

The evolution of the thermal niche is still an ecological riddle; natural selection shapes the thermal optimum, breadth of tolerance range and performance limit, but the correlations between these traits remain unknown, preventing an understanding of the ecological diversity of life (Mongold et al. 2008). An extension of this issue is whether species with a specific thermal range specialize at the same level along other niche axes (Sheth \& Angert 2014). To answer these questions, we analyzed how similar the preferences for different thermal and oxygenic conditions were within a community of rotifers. We also refer to an important demarcation line in the 
111 strategy of dealing with the environment, through a distinction between generalists, organisms

112 that display the relatively high and flat performance across environments, and specialists, those

113 that perform better in one type of environment than in all the others (Levins 1968). We examined

114 how species-specific standard body size was affected by the joint thermal and oxygenic

115 conditions of living. To find the subtle environmental cues for the possible size differences we

116 preceded with the multivariate analyses to reveal how the species preferences described by the

117 temperature and oxygen optima, ranges and tolerance limits were interrelated at the community

118 level. We predicted the species body size to be affected by both the temperature and oxygen.

119 We provide the first evidence of sharing the two-dimensional ecological niche, and of

120 interspecific evolutionary body size response to this niche, for the large community of aquatic

121 organisms.

\section{Material and methods}

124 Preparation of the dataset. Each rotifer species was characterized by eight parameters

describing its environmental preferences, namely, minimum/maximum/optimum/range of

126 temperature/oxygen concentration in the living habitat. We obtained data on these species-

127 specific parameters from two publications: Bērzinš and Pejler (1989a)(minimum, maximum,

128 optimum and range of tolerance to oxygen concentration) and Bērzinš and Pejler (1989b) (the

129 same parameters describing tolerance to temperature). We interpreted the values from the figures

130 using millimeter paper, with an accuracy of $0.5 \mathrm{mg} / \mathrm{L}$ for $\mathrm{O}_{2}$ and $1{ }^{\circ} \mathrm{C}$ for temperature. In both

131 cases, the tolerance range was calculated as max - min, while the optimal value was assumed to

132 be the value with the maximal abundance, as presented in the respective original figures. To

133 compare the variability within the environmental variables examined, we estimated the 
coefficient of quartile variation $(\mathrm{CQV})$, calculating $\left(Q_{3^{-}} Q_{1}\right) /\left(Q_{3}+Q_{1}\right)$, where $Q_{1}$ is a first quartile and $Q_{3}$ is a third quartile, for each variable separately.

The authors of the original articles did not provide data on the sizes of the species, but we were interested in the relative differences in rotifer species-specific body size rather than their local adaptations. Thus, we analyzed the association between the species standard body length $(\mu \mathrm{m})$ of rotifers, collected from the available databases, including Bielańska-Grajner et al. (2013), Bielańska-Grajner et al. (2015), Kreutz and Foissner (2006), Segers (1995), Segers and Shiel (2005) and the database from the website of the National Institute for Environmental Studies (http://www.nies.go.jp/), by searching for the species Latin name in a website browser. We standardized the length of the body by using the values provided for fixed, nonstretched individuals and excluding the length of toes and other appendages. In the cases when a size range was provided, we calculated the mean value. When more than one dataset was provided, especially for cited websites, we calculated the mean for all the subsources. The dataset for the 188 rotifer species, with the species-specific body lengths and sources of information, are provided in the supplementary materials (Table S1).

PCA analysis. To determine how the parameters describing the thermal and oxygenic preferences grouped at the interspecific level, we conducted the principal component analysis (PCA), with rows representing the species and columns represented by eight environmental parameters. We log-transformed and standardized the data to provide the correlation matrix and we conducted the analysis in CANOCO 5.0 (Ter Braak \& Šmilauer 2012).

Phylogenetic analysis. We performed all phylogenetic analyses in the R computational environment (v3.4.0) (R Core Team 2017). We obtained the phylogeny of 188 rotifer species from the open tree of life (Hinchliff et al. 2015) and 'rotl' package v3.0.3 (Michonneau et al. 2016). Because the branch lengths were not available, we automatically estimated them using a 
method proposed by Grafen (1989) and the ‘ape' package v4.1 (Paradis et al. 2004). All the path lengths from the root to the tips were equal. The tree contained polytomies, where more than two branches descended from a single node. Simulation studies have generally found that independent contrasts and phylogenetically generalized least squares (PGLS) are fairly robust to errors in both phylogenetic topology and branch length (Symonds \& Blomberg 2014). We tested the relationship between species body size (length, after natural logarithm transformation) and species-specific environmental characteristics in a phylogenetic comparative model. We applied PGLS using the gls() function in 'nlme' in the caper package (https://CRAN.Rproject.org/package=caper) considering body size as a response variable and four environmental parameters (ranges and optima) as explanatory variables. In the model, we assumed Brownian motion (BM) evolution, which is the most commonly assumed model of phenotypic evolution by comparative phylogenetic methods (Revell 2010; Lajeunesse \& Fox 2015). BM evolution treated random genetic drift as a primary process resulting in the loss of similarity from ancestral characteristics (Martins \& Garland 1991). Traits, e.g., body size and morphology, exhibit strong phylogenetic signals and most likely evolve by gradual changes over time according to the BM model of evolution (Symonds \& Blomberg 2014). We assumed the correlation structure based on Pagel's $\lambda$ (Pagel 1999) fixed at 1.

\section{Results}

\section{Thermo-oxygenic niche of rotifer assemblage}

PCA analysis showed three informative principal components (PCs) for data interpretation (eigenvalue > 1), explaining $37.47 \%$ (PC1), $29.17 \%(\mathrm{PC} 2)$ and $15.08 \%(\mathrm{PC} 3)$ of the variance (Fig. 1A, B). The evolutionary adaptation may be studied as a process or a product (Mongold et al. 2008). Treating the community of rotifers as a gene pool, we actually observed a product of 
evolution (Kimura 1974) at the assemblage level; the evolution of generalists was affected by both temperature and oxygen, as explained by PC1 (horizontally oriented arrows for temperature and oxygen tolerance ranges in Fig. 1A and their high loadings in Fig. 1B), and was clearly separated from the evolution of specialists, as explained by PC2 (vertically oriented arrows for temperature and oxygen optima in Fig. 1A and their high loadings in Fig. 1B). The generally opposite position of the parameters representing temperature vs. oxygen in PC2 (Fig. 1A, C) reflects the importance of their natural negative correlation in evolutionary processes. PC3 shows the ecological force of minor importance that caused a non-uniformity in the pattern of breath of thermal tolerance and hypoxia tolerance: according to PC3 the relationship between $\mathrm{T}_{\text {range }}$ and $\mathrm{O}_{2 \min }$ is positive, as compared to their negative link according to $\mathrm{PC} 1$ in Fig. $1 \mathrm{~B}$ ).

According to the CQV analysis, the lowest variability was observed for $\mathrm{T}_{\max }$, oxygen optimum $\left(\mathrm{O}_{2 \text { opt }}\right)$ and oxygen maximum $\left(\mathrm{O}_{2 \mathrm{max}}\right)$, followed by optimum temperature $\left(\mathrm{T}_{\mathrm{opt}}\right)$, temperature range $\left(\mathrm{T}_{\text {range }}\right)$, and oxygen tolerance range $\left(\mathrm{O}_{2 \text { range }}\right)($ Fig. 3C).

\section{Body size of species assembling the niche}

We tested the body size relationship to the parameters representing the PC1 (ranges) and PC2 (optima). Phylogenetically corrected regression analyses based on data obtained from the open tree of life (Hinchliff et al. 2015) for 188 species (Fig. 2) revealed that rotifer body size increased with increasing tolerance to oxygen range $\left(\mathrm{O}_{2 \text { range, }} \mathrm{p}<0.01\right.$; adjusted $\left.\mathrm{R}^{2}=0.054\right)$, decreased with increasing optimal temperature $\left(\mathrm{T}_{\mathrm{opt}}, \mathrm{p}<0.01\right.$; adjusted $\left.\mathrm{R}^{2}=0.048\right)$, and had no relationship with the remaining two parameters $\left(p=0.20\right.$ and adjusted $R^{2}=0.003$ for $T_{\text {range }}$ and $p=0.57$ and adjusted $\mathrm{R}^{2}=-0.004$ for $\mathrm{O}_{2 \text { opt }}$; Fig. 3). Body size evolved in response to both variables, temperature and oxygen, but the evolutionary cues for response were different; species were smaller when specializing to a high optimal temperature or to a narrow oxygen tolerance range (Fig. 3). 


\section{Discussion}

208 We found that within the rotifer community that involved 188 species of different ecology

209 (planktic, periphytic and benthic), representing various aquatic habitats (i) species-specific

210 thermal tolerance range and oxygen tolerance range evolved in the same direction, (ii) optima for

211 temperature and oxygen evolved in opposite directions. These results raise an intriguing question

212 regarding the possible different physiological mechanisms behind the selective forces of

213 adaptation to tolerance ranges $v s$. specialization to specific optima. They also mean that, in

214 general, a species characterized by the wide range of thermal tolerance should be expected to

215 have the wide range of tolerance to oxygen availability as well.

216 The analysis of body size relationship with eight environmental variables which describe the

217 thermo-oxygenic niche showed that, at the interspecific level, body size decreased in response to

218 both temperature and oxygen, but in different ways; the target of size response was optimum in

219 the case of temperature and the tolerance range in the case of oxygen.

220 The interspecific variability in each of the eight parameters shows that oxygen changes will affect

221 the organisms similarly to temperature changes as a consequence of the current climate changes.

222 Araújo et al. (2013) estimated the variance in cold tolerance $\left(\mathrm{CT}_{\min }\right)$ vs. heat tolerance $\left(\mathrm{CT}_{\max }\right)$ in

223 different groups of ectotherms. They found that the cold tolerance variance was almost twice as

224 high as the heat tolerance variance. Their interpretation of the results was that ectotherms are

225 more vulnerable to an increase in maximum temperatures than in minimum temperatures;

226 tolerance to cold is labile and subject to natural selection, whereas tolerance to heat is

227 physiologically conserved. In this respect, our results are in agreement; the tolerance to cold was

228 more variable than the tolerance to heat (7.82 vs. 5.98 of variance for $\mathrm{T}_{\min }$ and $\mathrm{T}_{\max }$, respectively).

229 A similar comparison between oxygen and temperature requires the use of a scale-independent 
parameter, such as CQV. Provided that the reasoning of Araújo et al. is correct, the rotifer community is most vulnerable to changes in these variables, while the least conserved are $\mathrm{T}_{\min }$ and low oxygen (hypoxia!) tolerance $\left(\mathrm{O}_{2 \mathrm{~min}}\right)$. The result obtained for species-specific oxygen optimum and maximum seems to be especially important considering the global ocean is undoubtedly warming (Cheng et al. 2019), and its oxygen concentration is decreasing through different synergistic mechanisms (Breitburg et al. 2018). Our CQV analysis showed that rotifer community appeared sensitive not only to potential changes in upper thermal limits $\left(\mathrm{T}_{\max }\right)$ but similarly much to oxygen deprivation below the optimal concentrations at which the species perform best $\left(\mathrm{O}_{2 \text { opt }}\right.$; Fig. 1C). This result acts as a specific warning: aquatic ectotherms are potentially very vulnerable to climate warming because the successive absolute reduction in oxygen concentration in water may be too challenging for them to quickly adapt. of the community in their natural habitat, we can actually observe the ecological, realized niche, which is a component of the fundamental niche remaining for usage in consequence of interactions with other organisms (Hutchinson 1957). Hence, it seems justified to claim that the here-studied rotifer community construct their ecological niche by detecting and responding to subtle environmental cues. Within their thermo-oxygenic niche, the parameters limiting the interspecific body size adjustment are maximal temperature, optimal oxygen and maximal

\section{Generalist-specialist continuum implications}

250 The PCA showed that evolution toward ranges of temperature and oxygen tolerance occurred separately from evolution toward specialization for high performance at pick values of both

252 parameters. This clear trade-off between evolution toward generalist and specialist strategies 
of distinguished patterns of adaptation to ranges of tolerance or specialization for certain optimal values, the simple observation of decreasing body size with increasing temperature within the thermo-oxygenic niche may be an outcome of two different physiological mechanisms leading to the same result: a large size at low temperatures and high relative oxygen availability and a small size at high temperatures and low relative oxygen availability (Fig. 4). This retorts to the matter whether decreasing in heat is indeed equivalent to increasing in cold (Walczynska et al. 2018). The former is driven by oxygen-limited aerobic metabolism (Woods 1999; Verberk et al. 2011) and may evolve along with a narrow tolerance to oxygen conditions (this study), while the latter may be driven by the limitation of proper genome maintenance in cold conditions (Xia 1995;

Woods et al. 2003; Hessen et al. 2013) and/or the energetic costs of cell membrane maintenance (Szarski 1983) and may reflect specialization toward a low optimal temperature. The existence of a common explanation for body size-to-temperature observations was questionable (Angilletta \& Dunham 2003; Angilletta Jr 2009). The dual causative mechanism we report here constitutes such a possible common, though complex, clarification.

\section{Global change implications}

It is imperative to elucidate whether the cues species experience are clear enough to respond. The warming effect is not symmetrical, as the minimum temperature is rising faster than its maximum (Easterling et al. 1997), and species with preferences for low optimal temperatures or high optimal oxygen concentrations are challenged differently than species with preferences in the upper thermal range. High optimal oxygen concentration is distinctive in this regard because species are apparently specialized for specific $\mathrm{O}_{2 \text { opt }}$ by some mechanisms alternative to the body size adjustment at the interspecific level (Fig. 3); neither they would be able to escape when facing a large-scale process of oxygen deprivation, such as global warming. With regard to the questions posed at the beginning of this text, our result on the high conservativity regarding 
preferred oxygen levels has important implications for conservation strategies. We should immediately start by focusing on saving the ecosystems with the highest risk of a sharp decline in oxygen availability.

To conclude, in this study we show that the community of aquatic animals displays clear preferences within a thermo-oxygenic niche, which reflects in the species-specific body size response to subtle cues of both environmental variables studied. This is the first evidence of such a clear pattern of within-community response to two-dimensional ecological niche, that may act as a base for any ecological large-scale studies and models, especially regarding the consequences of global warming. Our strong message is that oxygen should be taken into account as a variable similarly important to temperature, if we aim to understand, or to counteract, the effects of climatic changes on communities.

Acknowledgments: The authors are thankful to Ulf Bauchinger, Terézia Horváthová and Manuel Serra for the very helpful comments on the previous versions of this manuscript. This study would not be possible without the substantial work done long ago by Bruno Bērzinš and Birger Pejler.

Conflict of interests: The authors declare no conflict of interests.

\section{References}

Allen M.R., Dube O.P., Solecki W., Aragón-Durand F., Cramer W., Humphreys S., Kainuma M., Kala J., Mahowald N., Mulugetta Y., Perez R., Wairiu M. \& Zickfeld K. (2018). Framing and Context. In: Global Warming of $1.5^{\circ} \mathrm{C}$. An IPCC Special Report on the impacts of global warming of $1.5^{\circ} \mathrm{C}$ above pre-industrial levels and related global greenhouse gas emission 
pathways, in the context of strengthening the global response to the threat of climate change, sustainable development, and efforts to eradicate poverty (eds. Masson-Delmotte V, Zhai P, Pörtner H-O, Roberts D, Skea J, Shukla PR, Pirani A, Moufouma-Okia W, Péan C, Pidcock R, Connors S, Matthews JBR, Chen Y, Zhou X, Gomis MI, Lonnoy E, Maycock T, Tignor M \& Waterfield T). IPCC.

Angilletta Jr M.J. (2009). Thermal Adaptation. A Theoretical and Empirical Synthesis. Oxford University Press, Oxford.

Angilletta M.J. \& Dunham A.E. (2003). The temperature-size rule in ectotherms: Simple evolutionary explanations may not be general. American Naturalist, 162, 332-342.

Araújo M.B., Ferri-Yanez F., Bozinovic F., Marquet P.A., Valladares F. \& Chown S.L. (2013). Heat freezes niche evolution. Ecology Letters, 16, 1206-1219.

Atkinson D. (1994). Temperature and organism size - a biological law for ectotherms. Advances in Ecological Research, 25, 1-58.

Atkinson D., Morley S.A. \& Hughes R.N. (2006). From cells to colonies: at what levels of body organization does the 'temperature-size rule' apply? Evolution \& Development, 8, 202-214.

Begon M., Townsend C.R. \& Harper J.L. (2006). Ecology. From individuals to ecosystems. 4th edn. Blackwell Publishing.

Bergmann C. (1847). Uber die verhaltnisse der warmeokonomie der thiere zuihrer grosse.

Gottinger Studien, 1, 595-708.

Bērzinš B. \& Pejler B. (1989a). Rotifer occurence in relation to oxygen content Hydrobiologia, $183,165-172$.

Bērzinš B. \& Pejler B. (1989b). Rotifer occurence in relation to temperature Hydrobiologia, 175, $223-231$. 
Bielańska-Grajner I., Ejsmont-Karabin J. \& Iakovenko N. (2013). Wrotki. Rotifera, Bdelloidea. Lodz University Press, Lodz.

Bielańska-Grajner I., Ejsmont-Karabin J. \& Radwan S. (2015). Rotifers. Rotifera Monogononta.

Cheng L., Abraham J., Hausfather Z. \& Trenberth K.E. (2019). How fast are the oceans warming? Science, 363, 128-129.

Daufresne M., Lengfellner K. \& Sommer U. (2009). Global warming benefits the small in aquatic ecosystems. Proceedings of the National Academy of Sciences USA, 106, 12788-93. temperature trends for the globe. Science, 277, 364-367.

Forster J., Hirst A.G. \& Atkinson D. (2012). Warming-induced reductions in body size are greater in aquatic than terrestrial species. Proceedings of the National Academy of Sciences of the United States of America, 109, 19310-19314.

345 Grafen A. (1989). The phylogenetic regression. Philosophical Transactions of the Royal Society of London B, 326, 119-157. 
Horne C.R., Hirst A.G. \& Atkinson D. (2017). Seasonal body size reductions with warming covary with major body size gradients in arthropod species. Proceedings of the Royal Society BBiological Sciences, 284. seasonal temperature-size responses in copepods. Global Ecology and Biogeography, 25, 988999.

Huey R.B. \& Hertz P.E. (1984). Is a jack-of-all-temperatures a master of none? Evolution, 38, 441-444. Biology, 22, 415-427. changes in the body size of two rotifer species living in activated sludge follow the TemperatureSize Rule. Ecology and Evolution, 4, 4678-4689. Symposia on Quantitative Biology, 38, 515-524.

370 Kozłowski J. (2000). Does body size optimization alter the allometries for production and life 371 history traits? In: Scaling in biology (eds. Brown J. and West G.). Oxford University Press, pp. 237-252. 
Kozłowski J. (2006). Why life histories are diverse. Polish Journal of Ecology, 54, 585-605.

Kreutz M. \& Foissner W. (2006). The Sphagnum ponds of Simmelried in Germany: a biodiversity hot-spot for microscopic organisms. Protozoological monographs, 3, 1-267.

Lajeunesse M.J. \& Fox G.A. (2015). Statistical approaches to the problem of phylogenetically correlated data. In: Ecological Statistics: Contemporary theory and application (eds. Fox GA, Negrete-Yankelevich S \& Sosa VJ). Oxford University Press, pp. 261-283.

Levins R. (1968). Evolution in Changing Environments. Some Theoretical Explorations. Princeton University Press, Princeton.

Martins E.P. \& Garland T.J. (1991). Phylogenetic analyses of the correlated evolution of continuous characters: A simulation study. Evolution, 45, 534-557.

Michonneau F., Brown J.W. \& Winter D.J. (2016). rotl: an R package to interact with theOpen Tree of Life data. Methods Ecol Evol.

Mongold J.A., Bennett A.F. \& Lenski R.E. (2008). Experimental investigations of evolutionary adaptation to temperature In: Animals and temperature. Phenotypic and evolutionary adaptation (eds. Johnston IA \& Bennett AF). Cambridge University Press New York.

Pagel M. (1999). Inferring the historical patterns of biological evolution. nature, 401, 877-884.

Paradis E., Claude J. \& Strimmer K. (2004). APE: Analyses of Phylogenetics and Evolution in R language. Bioinformatics, 20, 289-90.

R Core Team (2017). R: a language and environment for statistical computing. $R$ Foundation for Statistical Computing, Vienna, Austria.

Revell L.J. (2010). Phylogenetic signal and linear regression on species data. Methods Ecol Evol, $1,319-329$.

Schmidt-Nielsen K. (1990). Animal physiology: Adaptation and environment. 4th edn. Cambridge University Press, Cambridge. 
Schwenk K., Padilla D.K., Bakken G.S. \& Full R.J. (2009). Grand challenges in organismal biology. Integrative and Comparative Biology, 49, 7-14.

Segers H. \& Shiel R.J. (2005). Tale of a sleeping beauty: a new and easily cultured model

Szarski H. (1983). Cell size and the concept of wasteful and frugal evolutionary strategies.

Journal of Theoretical Biology, 105, 201-209.

Taylor M.L., Skeats A., Wilson A.J., Price T.A.R. \& Wedell N. (2015). Opposite environmental and genetic influences on body size in the North American Drosophila pseudoobscura. BMC Evolutionary Biology, 15, 51.

Ter Braak C.J.F. \& Šmilauer P. (2012). Canoco reference manual and user's guide: software for ordination, version 5.0. Microcomputer Power, Ithaca, USA. ectotherms: Partial pressure and solubility together explain biodiversity and size patterns. Ecology, 92, 1565-1572.

419 Walczyńska A., Franch-Gras L. \& Serra M. (2017). Empirical evidence for fast temperature420 dependent body size evolution in rotifers. Hydrobiologia, 796, 191-200. 
Walczyńska A., Labecka A.M. \& Sobczyk M. (2018). What may a fussy creature reveal about body/cell size integration under stressful conditions? Development Genes and Evolution, 228, 179-188.

Walczyńska A., Labecka A.M., Sobczyk M., Czarnoleski M. \& Kozłowski J. (2015). The Temperature-Size Rule in Lecane inermis (Rotifera) is adaptive and driven by nuclei size adjustment to temperature. Journal of Thermal Biology, 54, 78-85.

Walczyńska A. \& Sobczyk Ł. (2017). The underestimated role of temperature-oxygen relationship in large-scale studies on size-to-temperature response. Ecology and Evolution, 7, 7434-7441.

Wetzel R.G. (2001). Limnology. Lake and river ecosystems. Elsevier Academic Press, San Diego, San Francisco, New York, Boston, London, Sydney, Tokyo.

Willmer P., Stone G. \& Johnston I.A. (2000). Environmental Physiology of Animals. Blackwell. Woods H.A. (1999). Egg-mass size cell size: effects of temperature on oxygen distribution. American Zoologist, 39, 244-252.

Woods H.A., Makino W., Cotner J.B., Hobbie S.E., Harrison J.F., Acharya K. \& Elser J.J. (2003). Temperature and the chemical composition of poikilothermic organisms. Functional Ecology, 17, 237-245.

Xia X.H. (1995). Body-temperature, rate of biosynthesis, and evolution of genome size Molecular Biology and Evolution, 12, 834-842. 


\section{Figure legends}

Fig. 1. The evolution of the thermo-oxygenic niche in 188 rotifer species. The results of the PCA analysis: A - factor plane (PC1-PC2) projection (each point represents a species), $\mathbf{B}$ - parameter loadings for PC1-PC3 in a multivariate space, $\mathbf{C}$ - coefficient of quartile variation (CQV) of each parameter represented by bubble size on the PC1/PC2 plane. The parameters are in the same order as in (A); temperature parameters are marked in red and oxygen parameters are in blue. The CQV value of each parameter is provided next to the respective bubble. Exemplary rotifer species are presented in $\mathbf{D}$.

Fig. 2. Phylogenetic tree for all rotifer species representing a dataset for those species with available phylogenetic data $(\mathrm{N}=188)$. Data were collected from the tree of life web project. The branch lengths were arbitrarily estimated using the method proposed by Grafen (1989) and the 'ape' package v4.1 (Paradis et al. 2004).

Fig. 3. Body size evolution toward a thermo-oxygenic niche in 188 rotifer species. The simple regression estimates of the relationship of body length with four environmental parameters that drove the PCA: ranges $(\mathrm{A}, \mathrm{B})$ and optima $(\mathrm{C}, \mathrm{D})$ of oxygen concentration and temperature. Each point represents an original value for a given species, while the estimation was phylogenetically corrected. Significant relationships are shown with their linear estimations.

Fig. 4. The thermo-oxygenic niche and its relationship to body size evolution in the assemblage of 188 rotifer species. The communities consist of large species at low temperature/high $\mathrm{O}_{2}$ conditions and small species at high temperature/low $\mathrm{O}_{2}$ conditions. This common observation may result from two compatible processes: low temperature may limit the small size, while low $\mathrm{O}_{2}$ availability may constrain the large size. We associated this pattern with the evolution toward the generalist or specialist strategy, which was clearly divided according to our PCA. The pattern of $\mathrm{O}_{2}$ decrease with increasing temperature (in water) is based on data from Wetzel (2001). 
bioRxiv preprint doi: https://doi.org/10.1101/2020.01.14.905901; this version posted January 15,2020 . The copyright holder for this preprint (which was not certified by peer review) is the author/funder, who has granted bioRxiv a license to display the preprint in perpetuity. It is made available under aCC-BY-NC-ND 4.0 International license.

Fig. 1.

A

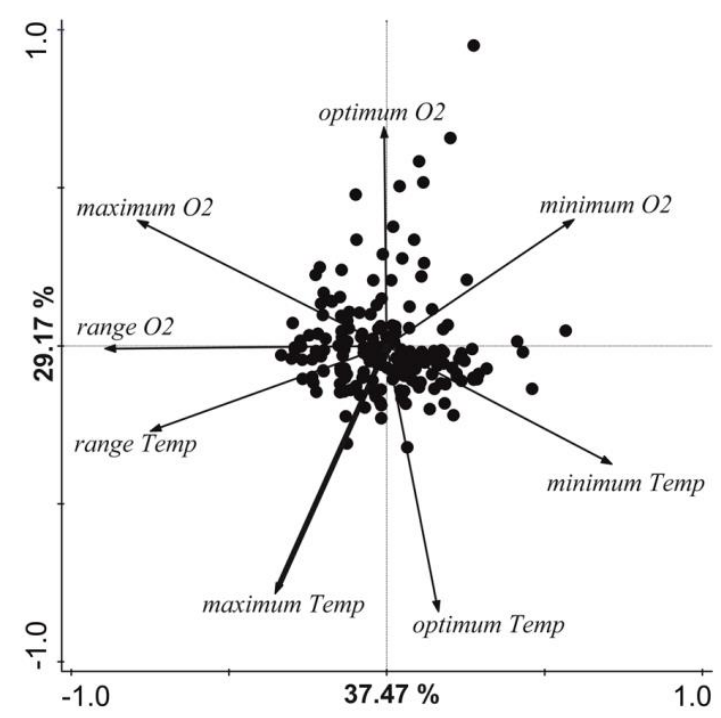

B

\begin{tabular}{|c|c|c|c|c|}
\hline & parameter & PC1 & PC2 & PC3 \\
\hline \multirow{4}{*}{$\begin{array}{l}\text { : } \\
\text { 말 }\end{array}$} & optimum & -0.008 & 0.693 & 0.270 \\
\hline & range & -0.894 & -0.008 & -0.400 \\
\hline & minimum & 0.593 & 0.400 & 0.581 \\
\hline & maximum & -0.790 & 0.397 & -0.139 \\
\hline \multirow{4}{*}{ 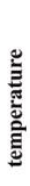 } & optimum & 0.164 & -0.841 & 0.148 \\
\hline & range & -0.750 & -0.270 & 0.554 \\
\hline & minimum & 0.714 & -0.375 & -0.426 \\
\hline & maximum & -0.353 & -0.784 & 0.324 \\
\hline
\end{tabular}

C

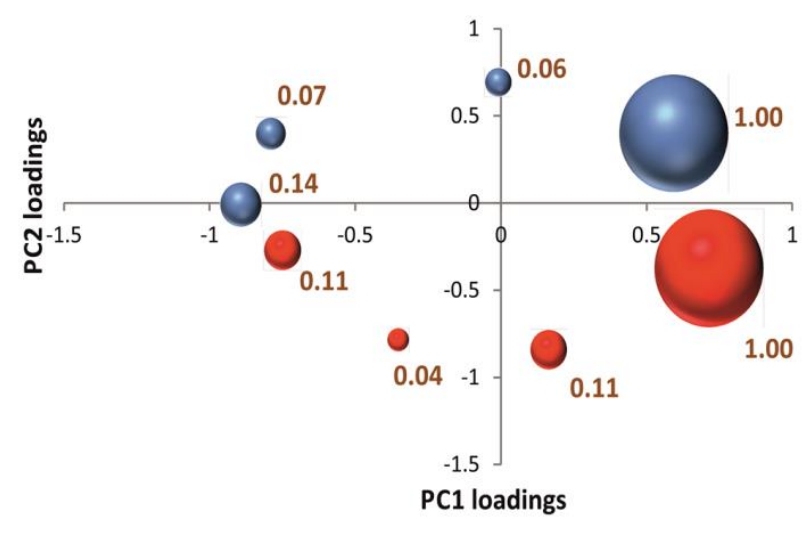

D

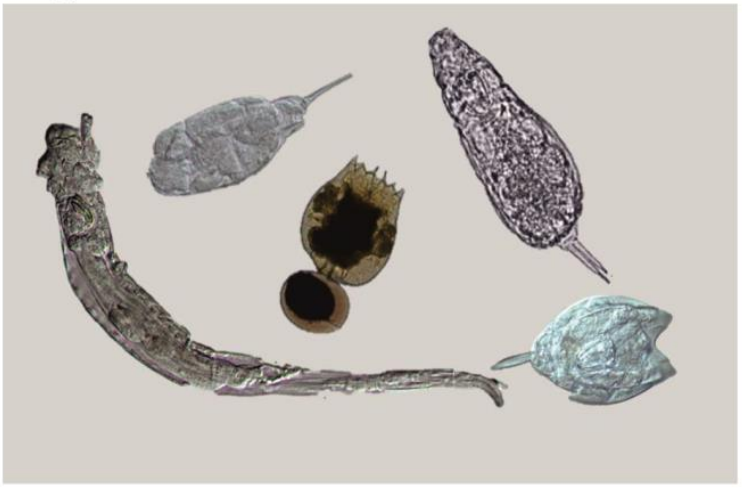


bioRxiv preprint doi: https://doi.org/10.1101/2020 01.14 905901. this version posted January 15, 2020. The copyright holder for this preprint (which was not certified by peer review) is the author/funder, who has granted bioRxiv a license to display the preprint in perpetuity. It is made available under aCC-BY-NC-ND 4.0 International license.

Fig. 2.

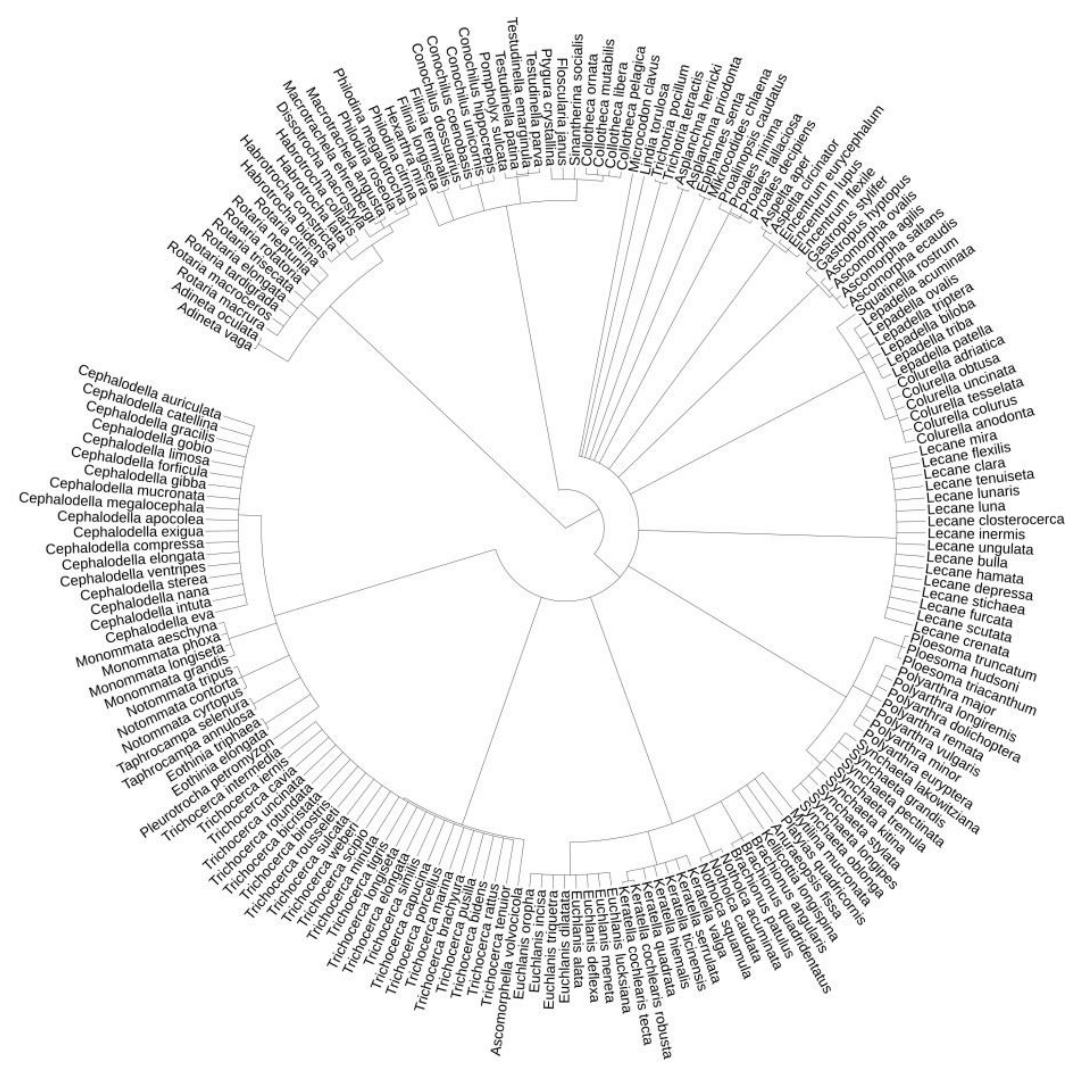


Fig. 3.
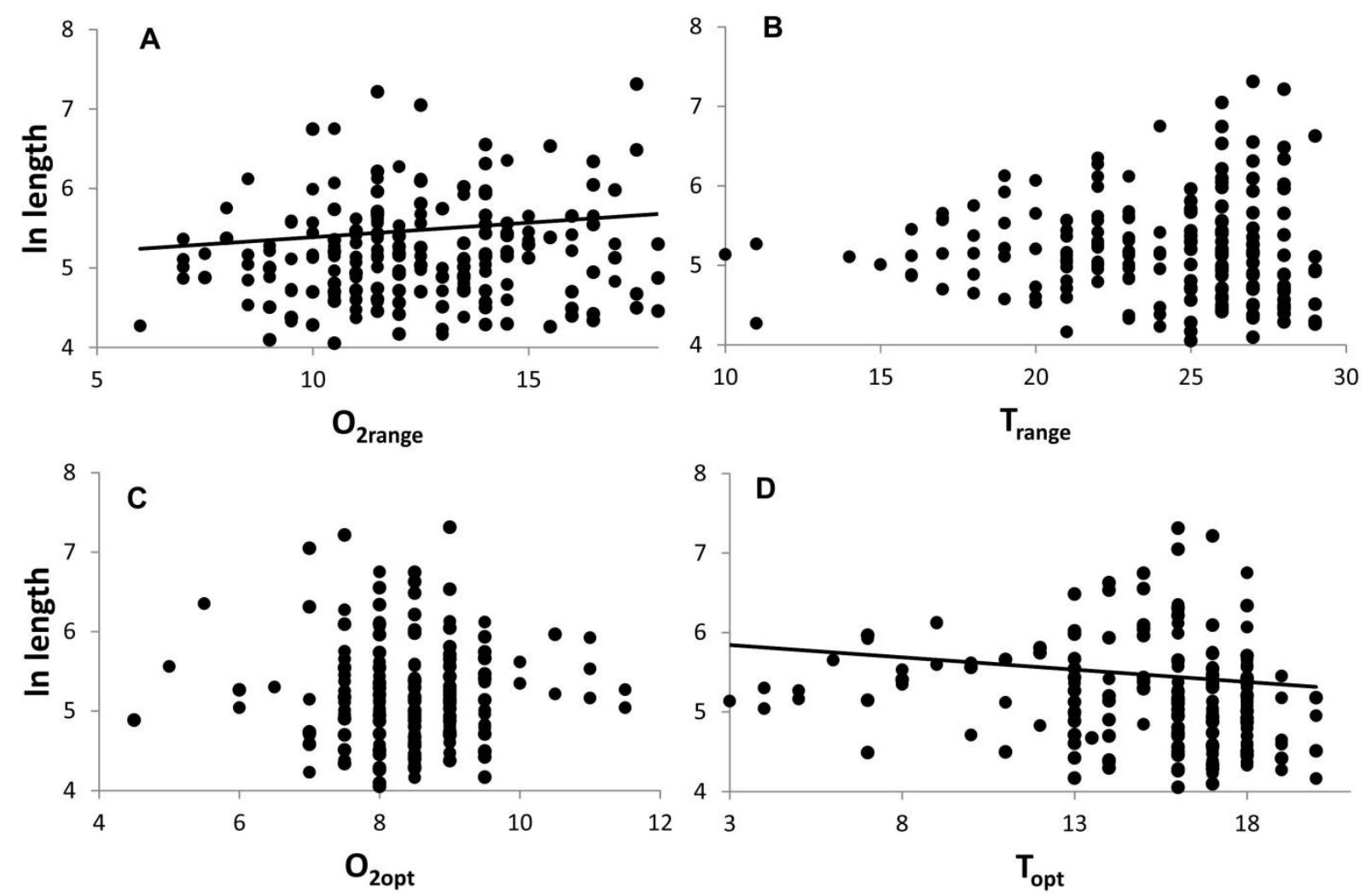
bioRxiv preprint doi: https://doi.org/10.1101/2020.01.14.905901; this version posted January 15,2020 . The copyright holder for this preprint (which was not certified by peer review) is the author/funder, who has granted bioRxiv a license to display the preprint in perpetuity. It is made available under aCC-BY-NC-ND 4.0 International license.

Fig. 4.

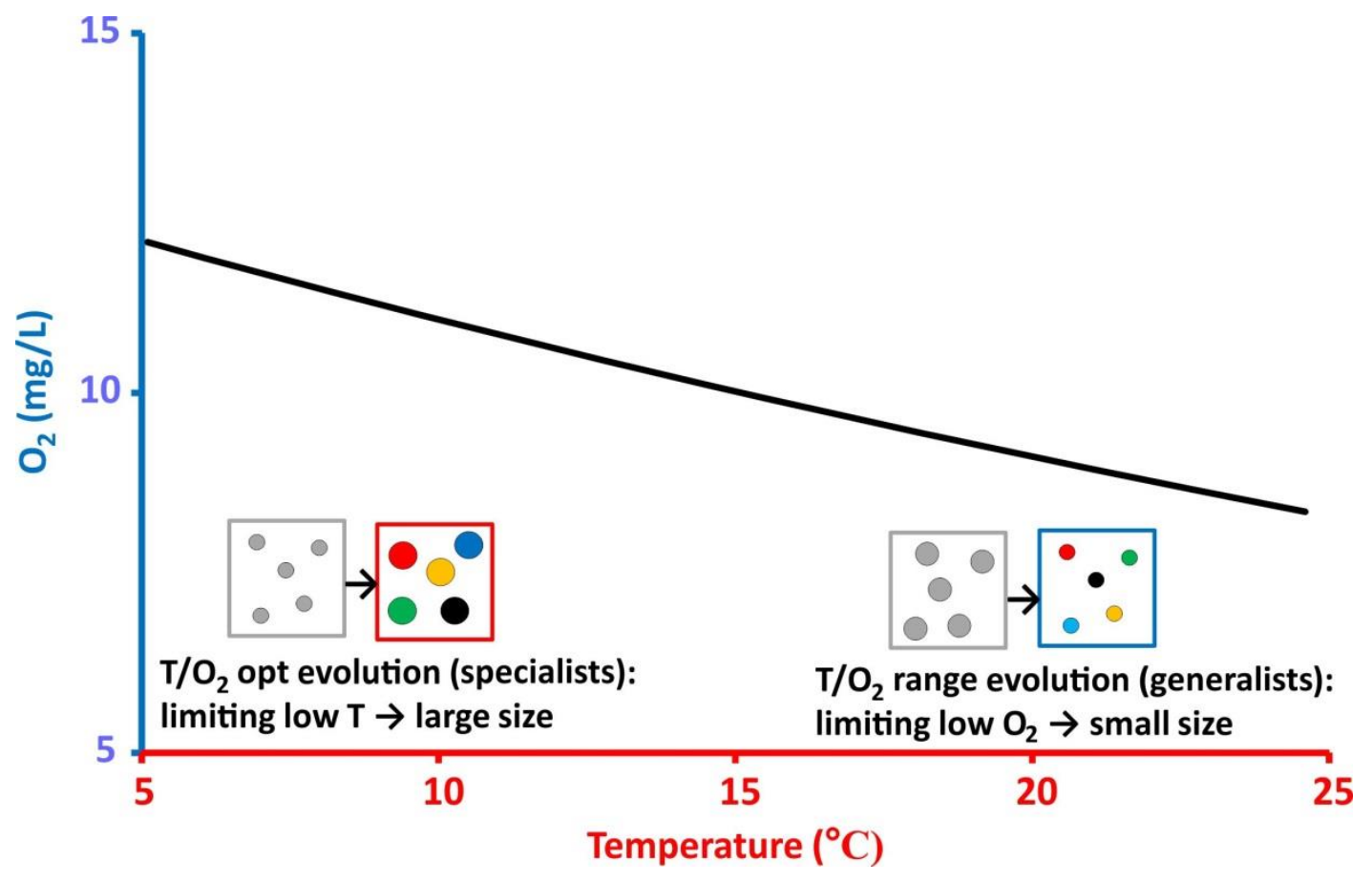

507 